\title{
Autonomy versus futility? Barriers to good clinical practice in end-of-life care: a Queensland case
}

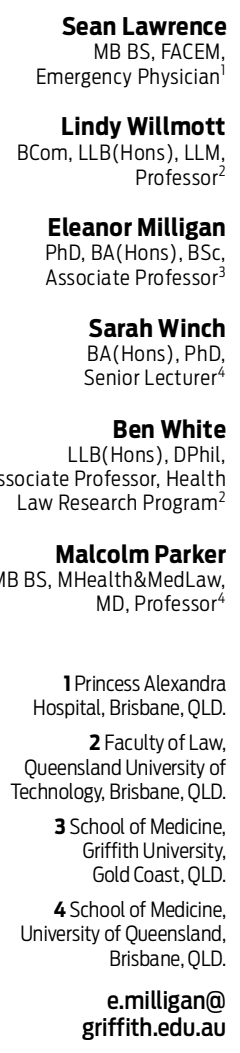

MJA 2012; 196: 404-405 doi: 10.5694/mja10.10969

Ethics and law p 406 and he Queensland coronial inquest into the death of June Woo $^{1}$ has highlighted the tensions between good clinical practice, the role of patient autonomy and substitute decision making, and the legitimate constraints placed on clinicians regarding provision of futile treatment. Here, we summarise the case and its legal implications and argue that improved communication between clinicians and families, as well as education of the community about the dying process, is needed to attain an acceptable outcome when clinicians and families initially disagree about treatment.

\section{Queensland law and the Coroner's findings}

The 2009 report of the coronial inquest into the death of June $W_{0 o}{ }^{1}$ provides the following case summary:

In the early evening of 14 November 2002, Mrs June Woo, an 82 year old woman with a history of pulmonary fibrosis and chronic respiratory failure, was admitted to the Princess Alexandra Hospital in Brisbane. She was assessed in the Emergency Department. Initially, she was minimally responsive. However, after an hour or so she become [sic] combative and was confused and distressed. She was sedated. At about midnight she was moved to a respiratory ward. At about $9.10 \mathrm{pm}$ the following night Mrs Woo stopped breathing. As a "not for resuscitation" order had been made the evening before, resuscitation was not attempted. One of the attending doctors later issued a cause of death certificate listing hyperkalaemia (higher than normal levels of potassium in the blood) as the principle [sic] cause of death. The family did not accept this and so, after some delay, the death was referred to the Brisbane Coroner for investigation.

\section{Findings about medical care and the not-for- resuscitation order}

The Coroner found that Mrs Woo's medical care was appropriate and that further interventions would have been unlikely to extend her life. However, the Coroner identified areas of concern relating to the process of making the notfor-resuscitation (NFR) order, including the extent and nature of the family's involvement in this decision. ${ }^{1}$

In Queensland, consent to health care for adults who lack decision-making capacity is governed by the Guardianship and Administration Act 2000 (GAA) and the Powers of Attorney Act 1998 - together constituting Queensland's "guardianship legislation". The guardianship legislation

\section{Summary \\ - Findings from a Queensland coronial inquest highlight the complex clinical, ethical and legal issues that arise in end-of-life care when clinicians and family members disagree about a diagnosis of clinical futility. \\ - The tension between the law and best medical practice is highlighted in this case, as doctors are compelled to seek family consent to not commence a futile intervention. \\ - Good communication between doctors and families, as well as community and professional education, is essential to resolve tensions that can arise when there is disagreement about treatment at the end of life.}

requires consent to carry out health care. Significantly, and somewhat paradoxically, "health care" is defined in the GAA (Schedule 2, s. 5) as including "withholding or withdrawal of a life-sustaining measure ... if the commencement or continuation of the measure... would be inconsistent with good medical practice". "Good medical practice" is defined by reference to recognised medical and ethical standards of the medical profession in Australia (Schedule 2, s. 5B). This means that consent is needed to withhold or withdraw a life-sustaining measure, even if providing that treatment would be inconsistent with good medical practice. $^{2}$ If the patient does not have an advance health directive, consent to health care must generally be obtained from a substitute decisionmaker on behalf of the patient (GAA, s. 66). In this case, consent from one or both of Mrs Woo's daughters was required before an NFR order could be made.

In light of the requirement for consent to withhold treatment, the Coroner examined how Mrs Woo's daughters were involved in the NFR decision. The evidence indicated that when the NFR order was made in the emergency department, the treating emergency physician "did not consider the decision was one the relatives could consent or object to" as further intervention was medically futile. ${ }^{1}$ The patient chart recorded: "family are aware of prognosis, has been visited by a priest". ${ }^{1}$ The Coroner found that the communication that occurred in the emergency department did not constitute consent by the daughters. As it is an offence under the GAA (s. 79) to carry out health care (including the withholding of health care) without obtaining consent, the Coroner indicated that, had the patient arrested in the emergency department and the NFR been followed, "significant legal consequences may have followed". Mrs Woo subsequently died in the respiratory ward, where 
cardiopulmonary resuscitation (CPR) was withheld as per the NFR order. The Coroner held that, by the time of the patient's death, there had been sufficient discussions with the daughters about the NFR order to constitute "tacit consent", making the NFR order lawful. ${ }^{1}$

\section{Recommendation about the hospital's not-for- resuscitation policy}

The Coroner also reviewed the hospital's NFR policy and was critical that it did not require consent from the appropriate decisionmaker for an NFR order to be obtained. He recommended the policy be reviewed to ensure compliance with the guardianship legislation, suggesting that a form be developed to ensure relevant consents are obtained. Partly in response to the Coroner's criticism of the hospital's NFR policy, Queensland Health developed an Acute Resuscitation Plan (ARP) form, ${ }^{3}$ which is now in use across Queensland. The ARP is completed

where it is reasonably expected that an adult patient $(\geqslant 18)$ may suffer an acute deterioration or critical event (e.g. cardiac or respiratory arrest) in the foreseeable future and require resuscitation planning.

\section{Implications for clinical practice}

The Coroner's findings outlined here create practical, professional and ethical challenges for medical staff who believe that resuscitation should not be provided in a particular case. From a clinical perspective, applying interventions such as CPR is inappropriate if no benefit will be achieved. Where doctors have consensus regarding futility of end-of-life care but disagree with the family, it appears, perhaps as an unintended consequence, that the guardianship legislation places clinicians in the difficult position of potentially having to choose between complying with the law and best medical practice. Legally compelling a doctor to seek consent to not commence a futile intervention may suggest that a choice exists when, in reality, death is inevitable. It has been argued that seeking consent to not actively treat may create misunderstanding and place an unwarranted burden on a family in crisis, including making them feel complicit in ending the life of their relative. ${ }^{4}$ Others argue that grieving people, including those experiencing anticipatory grief, may use denial as a method of coping, 5,6 which can significantly influence their ability to make decisions in the best interests of the dying patient.

For clinical staff, the requirement to provide resuscitation that they regard as futile creates physical demands and personal burdens that are recognised as factors contributing to emotional exhaustion and burnout. ${ }^{7,8}$ In some circumstances, such exhaustion and burnout can translate into poor staff retention, absenteeism, poor productivity and workplace conflict. ${ }^{9,10}$

While the Queensland law rightly preserves patient autonomy, it also has the potential to exacerbate the conditions for undignified and prolonged deaths. The refusal by a substitute decisionmaker to accept the inevitable death of a loved one may result in a dying patient receiving harmful invasive treatment.

In this complex debate, there are other important values and ethical perspectives to consider. The lack of consensus at times within the medical profession (and advanced specialties) on diagnosing clinical futility is particularly salient. Assessments of futility should include appraisal of the quality of life to be pursued and, as such, are not the sole remit of clinicians. Conversations with family regarding the patient's quality of life are necessary to decide whether treatment is futile for that individual. The current Queensland regulatory regime promotes — indeed requires - that engagement. Although the Queensland legislation contains a mechanism to resolve intractable disagreement between clinicians and family by requesting the Adult Guardian, a statutory officer, to consent to the withholding or refusal of treatment (GAA, s. 43), clinical experience suggests there are real practical difficulties in obtaining such decisions regarding end-of-life care that may be required within a few hours.

\section{Challenges of the legislation}

The coronial decision highlights challenges that exist under the current Queensland guardianship legislation: it conflicts with the common law that it replaced (consent to withhold or withdraw futile treatment not being required at common law), ${ }^{2}$ and it appears to be poorly understood by clinicians. ${ }^{11}$ In part because of this lack of familiarity, the legislation may also have broader implications for practices and policies regarding access to certain types of treatment, such as intensive care, in that a decision to not provide such care could be categorised as the withholding of a life-sustaining treatment and would therefore require family consent.

As reasonable people can have different views on whether treatment is futile in any given situation, good communication and community and professional education are crucial for resolving the tensions that arise when clinicians and family members initially disagree. Families need to be supported in making difficult decisions to withhold or withdraw treatment, and health professionals need to understand the legal imperative to provide that support.

Competing interests: Sean Lawrence was the emergency physician who initially treated the patient in this case. He is named in the publicly available Coroner's report. ${ }^{1}$ All information about the care of the patient in this article has been sourced directly from publicly available documentation and there has been no breach of patient confidentiality.

Provenance: Not commissioned; externally peer reviewed.

1 Barnes M, State Coroner. Inquest into the death of June Woo (COR 2713/02). Brisbane: Queensland Coroner's Court, 1 Jun 2009. http://www.courts.qld.gov.au/_data/assets/pdf_file/0003/131961/cif-woo-j20090601.pdf (accessed Jan 2012).

2 White B, Willmott L. Issue 11: A requirement to provide futile treatment? In: Rethinking life-sustaining measures: questions for Queensland. Brisbane: Queensland University of Technology, 2005: 69-72. http://eprints.qut.edu.au/7093/1/7093_l.pdf (accessed Jan 2012).

3 Queensland Health. Quick guide to completing an Acute Resuscitation Plan (ARP). http:// apps.health.qld.gov.au/acp/Public_Section/pdf_QuickGuide.pdf (accessed Jan 2012).

4 Murphy BF. What has happened to clinical leadership in futile care discussions? Med J Aust 2008; 188: $418-419$

5 Holley CK, Mast BT. The impact of anticipatory grief on caregiver burden in dementia caregivers. Gerontologist 2009; 49: 388-396.

6 Weissman DE. Decision making at a time of crisis near the end of life. JAMA 2004; 292: 1738-1743.

7 Meltzer LS, Huckabay LM. Critical care nurses' perceptions of futile care and its effect on burnout. Am J Crit Care 2004; 13: 202-208.

8 Ferrell BR. Understanding the moral distress of nurses witnessing medically futile care. Oncol Nurs Forum 2006; 33: 922-930.

9 Schluter J, Winch S, Holzhauser K, Henderson A. Nurses' moral sensitivity and hospital ethical climate: a literature review. Nurs Ethics 2008; 15: 304-321.

10 Marco CA, Bessman ES, Kelen GD. Ethical issues of cardiopulmonary resuscitation: comparison of emergency physician practices from 1995 to 2007. Acad Emerg Med 2009; 16: 270-273.

11 Parker M. Futile choices: Wooing doctors to acknowledge the law in Queensland. J Law Med 2010; 18:32-37. ـ 